\title{
How to increase online trust and user experience for legal services
}

\author{
Deborah Whittle \\ The University of Sunderland \\ Sunderland, UK \\ deborah@deborahwhittle.co.uk
}

\begin{abstract}
This research looks at online trust, and what features affect trust, both perceived and actual. A set of heuristics were drawn from a systematic review of 160 papers on trust. The heuristics were then used for an audit of 40 UK legal websites. Five mock legal websites were created using features found on real legal sites. These mock websites will be used to measure the impact of the different designing features on trust. The sites will then be tested by both the solicitors and end-users.
\end{abstract}

Trust, Online trust, Legal services, Heuristics

\section{INTRODUCTION}

Online businesses success is determined in part by the consumers' ability and willingness to trust the supplier. There is a perception that there is a risk involved with information disclosure. Therefore it is essential that the user feels that the entity collecting personal data can be trusted(Beldad et al., 2012). Trust is an important component during a transaction when there is any uncertainty, anonymity or if the user feels any lack of control, such as sharing sensitive personal or financial information (Bhattacherjee, 2002).

Trust is especially relevant to legal services, only lawyers can foster this trust, and by delivering a trustworthy service, they are building for the client, not just trust in their firm but trust in the legal system (Mah, 2005). People who need help seek a good lawyer and the most efficient way for a lawyer to gain new business is to signal trustworthiness. Lin Wu et al. (2016) stated that further research is needed where heuristics can be used to evaluate trust in real-world situations and effective risk communication (Lin Wu et al., 2016). Heuristics are simply short cuts to ease the cognitive load of decision making (Lin Wu et al., 2016).

In the 1990's Jakob Nielson and Rolf Molich developed a heuristic evaluation this method was designed to be an informal method of usability analysis and is still widely used by software developers and UX Designers, he found that without heuristics individuals would only find 20$51 \%$ of the usability problems (Nielsen and Molich, 1990). A systematic literature review was completed, thereby identifying evaluating and interpreting results relevant to a particular research problem (Kitchenham and Brereton, 2013). The research question applied to the systemic review was "what features facilitated online trust" so the descriptors adopted were "trust" and "online trust" in Boolean search in titles, abstracts and keywords. For publications starting in 1967-2020, using The University of Sunderland's, Library services, limiter was "full text", and source type was "academic journals". With a subject of "internet", "information technology"," trust". This identified 1,451 articles. The inclusions criteria were (a) articles with a clear description of features that affect online users trust, (b) articles that explained what trust is. After reviewing the paper 160 , were used for the full study, by reviewing the literature, eight heuristics where compiled, which has been shown to affect online trust.

\section{TRUST HEURISTICS}

- Image content should contain people, they should not contain any negative images (Riaz et al., 2018), and there should be no missing images (Cyr et al., 2009; Clare AM Sutherland et al., 2015; Joyner et al., 2018; Schultz et al., 2018) and images should be of a good quality (Lian and Yu, 2019)

- Trust transfer is an effective mechanism in brick and clicks cases (Chun-Chia Wang and Chang-Cheng Sie, 2012; Xiao, Zhang and $\mathrm{Fu}, 2019$ ), by being able to demonstrate that the firm is a real 
company by providing an office telephone number (Beatty et al., 2011), a real address, directions of how to find the office, display images of real staff members and premises, will increase trust and create synergies between the physical and online part of the business (Nicholls, 2004; Doong, Wang and Foxall, 2011; Lee, Chung and Lee, 2011; Mesch, 2012; Toufaily, Souiden and Ladhari, 2013)

- Sites should include visible trust features, also known as trust cues, that reduce the risk for the user, for example, $3^{\text {rd }}$ Party recommendations, accreditations, awards, strong brand and reviews (Beldad et al., 2012; Bonsón Ponte, Carvajal-Trujillo and Escobar-Rodríguez, 2015; Rose

Sebastianelli and Nabil Tamimi, 2018; Akhtar et al., 2019; Guillermo Carbonell et al., 2019)

- Sites should be easy to use and have a good user flow because when they are, users perceive it as "having received a good service" this feeling increase trust and the like hood of repeat business (Benamati et al., 2010; Reynolds and Ruiz de Maya, 2013; Mahnke, Benlian and Hess, 2015; Demangeot and Broderick, 2016; Jen-Hwa Hu, Han-fen and Xiao, 2017; Trivedi and Yadav, 2018; Ageeva et al., 2019).

- Firms should provide proof of their ability, i.e. cv, qualifications, case history, this reduces the risk for their clients and increase trust (Bhattacherjee, 2002; Koufaris and Hampton-Sosa, 2004; Baoling $\mathrm{Hu}$ and Le-xing Yun, 2010; Ismunandar Ismunandar and Mulyadin Mulyadin, 2018; Song and Bitektine, 2018)

- Having a Modern site, that is visually appealing is a vital determinant to trust, especially if it is a new client (Shneiderman et al., 2014; Pengnate and Sarathy, 2017; Franco Valdez, Valdez Cervantes and Motyka, 2018). The Highquality design evokes thoughtful, deliberate secure behaviour (Grimes and Marquardson, 2019), furthermore, there is also a strong link between satisfaction and loyalty (Faisal et al., 2017). Sites should offer a multi-channel approach to improve online visibility (Lian and $Y u, 2019$ ) and have good SEO so that they can be found easily

- The site must be actual secure and available, Security features and privacy statements are indications of the actual trustworthiness on the online firm (Beldad et al., 2012; Bonsón Ponte, CarvajalTrujillo and Escobar-Rodríguez, 2015)
- The firm should show benevolence, as is one of the three key dimensions of trust (Murphy and Blessinger, 2003; Yousafzai, Pallister and Foxall, 2003; Hung, Cheng and Chen, 2012; Oliveira et al., 2017)this could be done by offering free advice (Brengman and Karimov, 2012)

\section{APPLYING THE METHODOLOGY}

A total of 40 real legal sites were tested with the heuristics, which was moderated by a score sheet. Each Heuristics was awarded a score from 0-5 which was then added to a table so that areas that had common faults could be understood. Each site took approximately 2 hours, 7 minutes to evaluate.

\section{RESULTS}

\subsection{The trust features found in Legal Sites}

The best sites had images of people interacting, the words and images wherein harmony and care had been taken in presenting staff images in a coordinated way. All the images were Next-Gen formats JPEG2000, JPEG XR or WebP. The images were the correct size and optimised for the web.

The branch was able to show brick and clickability by giving a real address along with contact information, displaying information about car parking or bus numbers. They showed opening hours and which team members worked at the branch alongside a google map, offering directions.

Visible trust features such as Lexcel awards were evident and that the Solicitors Regulation Authority regulated many sites. Firms showed third-party accreditations and had a strong branding strategy.

It was apparent which services they offered, and there was a good user flow. The menu was nicely designed and did not use legal terms. Modern sites had excellent staff profiles which showed what awards or accreditation each staff member with a comprehensive case history and cv and linked to their linked in profile.

Modern sites were Search Engine Optimised (SEO), with outstanding security and had correctly installed the SSL certificate to all pages, all links where to HTTPS pages. The JavaScript was free from any vulnerabilities.

Benevolent sites displayed mentoring schemes and information about fundraising for chosen charities. They also offered free advice and had video links to advice as well as free PDF 
downloads or had useful information blogs. Some offered helpful tools; others offered fixed-fee pricing structures or payment options. Most of the high scoring benevolent sites had caring mission statements.

\subsection{The worst errors found on legal sites.}

The worst legal sites had a disconnection between the text and the carousels images. Some sites had negative images, such as parents fighting. Research has shown that emotionally negative images will cause people to skip webpages. One site had an image of physical abuse. A common problem found was missing personnel images, the generic blank person image should be avoided not being able to see a person's face, affects users trust and the solicitor with the missing image is not likely to be contacted. Instead of using a blank figure, use the company logo or image of the office, this looks less intimidating. Some sites had blurry images.

Some sites had used legal terms on the navigation menus, such as "Private Client" a user would not understand the meaning, making the site unfathomable. Another site had 1076 links, by adding too many links to a site or too many buttons and menus, the site will be confusing to the user.

The worst sites had no staff profile at all, so it was impossible to gauge if they were capable solicitors.

Some of the older legal sites felt bland and textheavy compared to the more modern interactive sites; new sites need to offer the user a joyful experience. Some sites had low scores for search engine optimisation, which would make them hard to find. A number of the sites had colour palettes where questionable.

The basic security of legal sites is worrying, over $1 / 8$ of the tested sites where insecure, some had no SSL certification, others linked to insecure sites. A few had known JavaScript vulnerabilities. This should be investigated further in future research.

Firms that were not benevolent did not show any charity work or any pro-bono and were vague about pricing. Benevolence is an essential part of the user's trust; users must feel that the company will act from them rather than just maximise profit for the company.

\section{CONCLUSION}

The Image scores were the poor across legal sites for all categories.

Most firms were good at showing the firm's thirdparty accreditations. Brick and click's scores were also excellent, with most firms having a real business address. However, many legal firms did not invest much effort in showing their staff's ability, which was a surprising result given that for legal firms, the quality of their solicitors is paramount, as they are a service. Security was also an issue and likewise, benevolence. The modern score included SEO, which is vital to ensure that the legal site is found via search engines. Future work to be done later this year involves user testing of the trust heuristics to explore the different impacts on the users.

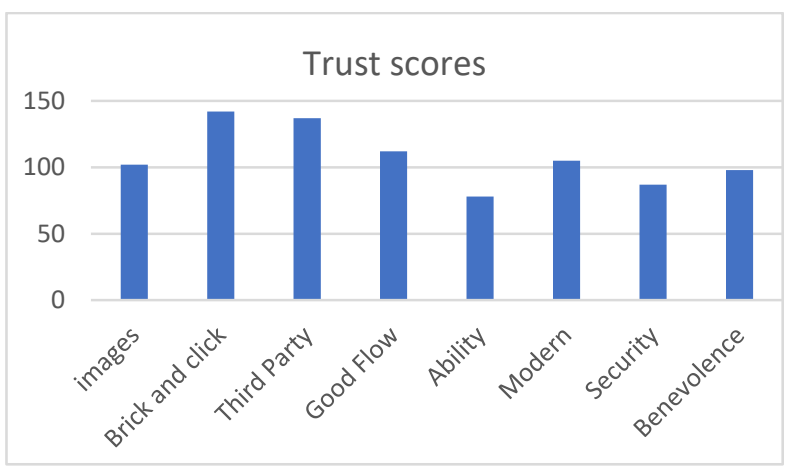

\section{REFERENCES}

Ageeva, E. et al. (2019) 'Cues adopted by consumers in examining corporate website favorability: An empirical study of financial institutions in the UK and Russia', Journal of Business Research, 98, pp. 15-32. doi: 10.1016/j.jbusres.2018.12.079.

Akhtar, N. et al. (2019) 'Mechanisms of consumers' trust development in reviewers' supplementary reviews: A reviewer-reader similarity perspective', Tourism Management Perspectives, 31, pp. 95-108. doi: 10.1016/j.tmp.2019.04.001.

Bao-ling $\mathrm{Hu}$ and Le-xing Yun (2010) 'Empirical Research on the Influencing Factors of Online Customer Trust', 2010 International Conference on Management and Service Science, Management and Service Science (MASS), 2010 International Conference on, pp. 1-3. doi: 10.1109/ICMSS.2010.5576803.

Beatty, P. et al. (2011) 'Consumer trust in ecommerce web sites', ACM Computing Surveys, 43(3), pp. 1-46. doi: 10.1145/1922649.1922651.

Beldad, A. et al. (2012) 'A cue or two and I'll trust you: Determinants of trust in government organizations in terms of their processing and usage of citizens' personal information disclosed online', Government Information Quarterly, 29(1), pp. 41-49. doi: 10.1016/j.giq.2011.05.003.

Benamati, J. "Skip" et al. (2010) 'Clarifying the Integration of Trust and TAM in E-Commerce 
Environments: Implications for Systems Design and Management', IEEE Transactions on Engineering Management, 57(3), pp. 380-393. doi: 10.1109/TEM.2009.2023111.

Bhattacherjee, A. (2002) 'Individual Trust in Online Firms: Scale Development and Initial Test', Journal of Management Information Systems, 19(1), pp. 211-241. doi: 10.1080/07421222.2002.11045715.

Bonsón Ponte, E., Carvajal-Trujillo, E. and Escobar-Rodríguez, T. (2015) 'Influence of trust and perceived value on the intention to purchase travel online: Integrating the effects of assurance on trust antecedents', Tourism Management, 47, pp. 286-302. doi: 10.1016/j.tourman.2014.10.009.

Brengman, M. and Karimov, F. P. (2012) 'The effect of web communities on consumers' initial trust in B2C e-commerce websites', Management Research Review, 35(9), p. 791.

Chun-Chia Wang and Chang-Cheng Sie (2012) 'A Study of Consumers' Trust in Online Shopping between Pick-up Goods Behavior in the Convenience Stores', 2012 26th International Conference on Advanced Information Networking and Applications Workshops, Advanced Information Networking and Applications Workshops (WAINA), 2012 26th International Conference on, pp. 381-386. doi: 10.1109/WAINA.2012.7.

Clare AM Sutherland et al. (2015) 'Personality judgments from everyday images of faces', Frontiers in Psychology, Vol 6 (2015). doi: 10.3389/fpsyg.2015.01616/full.

Cyr, D. et al. (2009) 'Exploring Human Images in Website Design: A Multi-Method Approach', MIS Quarterly, 33(3), pp. 539-A9. doi: $10.2307 / 20650308$.

Demangeot, C. and Broderick, A. J. (2016) 'Engaging customers during a website visit: a model of website customer engagement', International Journal of Retail \& Distribution Management, 44(8), pp. 814-839. doi: 10.1108/IJRDM-08-2015-0124.

Doong, H.-S., Wang, H.-C. and Foxall, G. R. (2011) 'An investigation of consumers' webstore shopping: A view of click-and-mortar company', International Journal of Information Management, 31(3), pp. 210-216. doi: 10.1016/j.jinfomgt.2010.06.006.

Faisal, C. M. N. et al. (2017) 'Web Design Attributes in Building User Trust, Satisfaction, and Loyalty for a High Uncertainty Avoidance Culture', IEEE Transactions on HumanMachine Systems, 47(6), pp. 847-859. doi: 10.1109/THMS.2016.2620901.
Franco Valdez, A. D., Valdez Cervantes, A. and Motyka, S. (2018) 'Beauty is truth: The effects of inflated product claims and website interactivity on evaluations of retailers' websites', Journal of Business Research, 90, pp. 67-74. doi: 10.1016/j.jbusres.2018.04.027.

Grimes, M. and Marquardson, J. (2019) 'Quality matters: Evoking subjective norms and coping appraisals by system design to increase security intentions', Decision Support Systems, 119, pp. 23-34. doi: 10.1016/j.dss.2019.02.010.

Guillermo Carbonell et al. (2019) 'The impact of emotionality and trust cues on the perceived trustworthiness of online reviews', Cogent Business \& Management, (1). doi: 10.1080/23311975.2019.1586062.

Hung, S.-W., Cheng, M.-J. and Chen, P.-C. (2012) 'Reexamining the Factors for Trust in Cultivating Online Customer Repurchase Intentions: The Moderating Effect of Perceived Waiting', International Journal of HumanComputer Interaction, 28(10), pp. 666-677. doi: 10.1080/10447318.2011.654201.

Ismunandar Ismunandar and Mulyadin Mulyadin (2018) 'The Effect of Trust Dimension to ECommerce Costumers Participation (Case Study to E-Commerce Costumers in Bima City)', Jurnal Terapan Manajemen dan Bisnis, (2), p. 138. doi: 10.26737/jtmb.v4i2.833.

Jen-Hwa Hu, P., Han-fen, H. and Xiao, F. (2017) 'Examining the Mediating Roles of Cognitive Load and Performance Outcomes in User Satisfaction with a Website: A Field QuasiExperiment', MIS Quarterly, 41(3), pp. 975A11.

Joyner, L. et al. (2018) 'Exploring emotional response to images used in agritourism destination marketing', Journal of Destination Marketing \& Management, 9, pp. 44-55. doi: 10.1016/j.jdmm.2017.10.004.

Kitchenham, B. and Brereton, P. (2013) 'A systematic review of systematic review process research in software engineering', Information \& Software Technology, 55(12), pp. 20492075. doi: 10.1016/j.infsof.2013.07.010.

Koufaris, M. and Hampton-Sosa, W. (2004) 'The development of initial trust in an online company by new customers', Information \& Management, 41(3), pp. 377-397. doi: 10.1016/j.im.2003.08.004.

Lee, K. C., Chung, N. and Lee, S. (2011) 'Exploring the influence of personal schema on trust transfer and switching costs in brick-andclick bookstores', Information \& Management, 
$48(8)$

pp. 364-370.

doi: 10.1016/j.im.2011.09.002.

Lian, T. and Yu, C. (2019) 'Impacts of online images of a tourist destination on tourist travel decision', Tourism Geographies, 21(4), pp. 635-664. doi: 10.1080/14616688.2019.1571094.

Lin Wu et al. (2016) 'Affect Heuristic as a Function of Trust in Risk Communication', Social Behavior \& Personality: an international journal, 44(4), pp. 619-630.

Mah, L. (2005) 'The Legal Profession Faces New Faces: How Lawyer's Professional Norms Should Change to Serve a Changing American Population', California Law Review, 93(6), pp. 1721-1772.

Mahnke, R., Benlian, A. and Hess, T. (2015) 'A Grounded Theory of Online Shopping Flow', International Journal of Electronic Commerce, 19(3), pp. 54-89. doi: 10.1080/10864415.2015.1000222.

Mesch, G. S. (2012) 'Is online trust and trust in social institutions associated with online disclosure of identifiable information online?', Computers in Human Behavior, 28(4), pp. 1471-1477. doi: 10.1016/j.chb.2012.03.010.

Murphy, G. B. and Blessinger, A. A. (2003) 'Perceptions of no-name recognition business to consumer e-commerce trustworthiness: the effectiveness of potential influence tactics', Journal of High Technology Management Research, 14(1), p. 71. doi: 10.1016/S10478310(03)00005-1.

Nicholls, M. H. (2004) 'Georgetown Journal of Legal Ethics Current Developments 2004-2005 A Quagmire of Internet Ethics Law and the ABA Guidelines for Legal Website Providers', Georgetown Journal of Legal Ethics, 18(3), pp. 1021-1040.

Nielsen, J. and Molich, R. (1990) 'Heuristic evaluation of user interfaces', in Proceedings of the SIGCHI conference on Human factors in computing systems Empowering people - $\mathrm{CHI}$ '90. the SIGCHI conference, Seattle, Washington, United States: ACM Press, pp. 249-256. doi: 10.1145/97243.97281.

Oliveira, T. et al. (2017) 'Full length article: Modelling and testing consumer trust dimensions in e-commerce', Computers in Human Behavior, 71, pp. 153-164. doi: 10.1016/j.chb.2017.01.050.

Pengnate, S. (Fone) and Sarathy, R. (2017) 'An experimental investigation of the influence of website emotional design features on trust in unfamiliar online vendors', Computers in
Human Behavior, 67, pp. 49-60. doi: 10.1016/j.chb.2016.10.018.

Reynolds, N. and Ruiz de Maya, S. (2013) 'The impact of complexity and perceived difficulty on consumer revisit intentions', Journal of Marketing Management, 29(5-6), pp. 625-645. doi: 10.1080/0267257X.2013.774290.

Riaz, A. et al. (2018) 'The interplay between emotion, cognition and information recall from websites with relevant and irrelevant images: A Neuro-IS study', DECISION SUPPORT SYSTEMS, 111, pp. 113-123. doi: 10.1016/j.dss.2018.05.004.

Rose Sebastianelli and Nabil Tamimi (2018) 'Etailer website attributes and trust: understanding the role of online reviews', Online Information Review, 42(4), pp. 506-519. doi: 10.1108/OIR-02-2016-0039.

Schultz, T. et al. (2018) 'The effect of images on community engagement with sustainable stormwater management: The role of integral disgust and sadness', Journal of Environmental Psychology, 59, pp. 26-35. doi: 10.1016/j.jenvp.2018.08.003.

Shneiderman, B. et al. (2014) Designing the user interface: strategies for effective humancomputer interaction. Pearson new international edition. Harlow, England: Pearson (Pearson custom library). Available at: http://catalogue.sunderland.ac.uk/items/410167 (Accessed: 9 July 2018).

Song, F. and Bitektine, A. (2018) 'Firm Status and Evaluators' Trust: The Many Ways to Trust a Firm', Journal of Business Ethics, 153(2), pp. 503-518. doi: 10.1007/s10551-016-3334-0.

Toufaily, E., Souiden, N. and Ladhari, R. (2013) 'Consumer trust toward retail websites: Comparison between pure click and click-andbrick retailers', Journal of Retailing and Consumer Services, 20(6), pp. 538-548. doi: 10.1016/j.jretconser.2013.05.001.

Trivedi, S. K. and Yadav, M. (2018) 'Predicting online repurchase intentions with e-satisfaction as mediator: a study on Gen Y', VINE: The Journal of Information \& Knowledge Management Systems, 48(3), p. 427.

Xiao, L., Zhang, Y. and Fu, B. (2019) 'Exploring the moderators and causal process of trust transfer in online-to-offline commerce', Journal of Business Research, 98, pp. 214-226. doi: 10.1016/j.jbusres.2019.01.069.

Yousafzai, S. Y., Pallister, J. G. and Foxall, G. R. (2003) 'A proposed model of e-trust for electronic banking', Technovation, 23(11), p. 847. doi: 10.1016/S0166-4972(03)00130-5. 